\title{
Alphonse de Lamartine, Correspondance. Lettres d'Alix de Lamartine. Lettres de Louis de Vignet
}

Lise Sabourin

\section{CpenEdition}

\section{Journals}

Édition électronique

URL : http://journals.openedition.org/studifrancesi/7975

DOI : 10.4000/studifrancesi.7975

ISSN : 2427-5856

Éditeur

Rosenberg \& Sellier

\section{Édition imprimée}

Date de publication : 1 juillet 2009

Pagination : 414

ISSN : 0039-2944

\section{Référence électronique}

Lise Sabourin, «Alphonse de Lamartine, Correspondance. Lettres d'Alix de Lamartine. Lettres de Louis de Vignet », Studi Francesi [En ligne], 158 (LIII | II) | 2009, mis en ligne le 30 novembre 2015, consulté le 12 janvier 2021. URL : http://journals.openedition.org/studifrancesi/7975 ; DOI : https://doi.org/10.4000/ studifrancesi.7975

Ce document a été généré automatiquement le 12 janvier 2021.

\section{cc)}

Studi Francesi è distribuita con Licenza Creative Commons Attribuzione - Non commerciale - Non opere derivate 4.0 Internazionale. 


\title{
Alphonse de Lamartine, Correspondance. Lettres d'Alix de Lamartine. Lettres de Louis de Vignet
}

\author{
Lise Sabourin
}

\section{RÉFÉRENCE}

ALPHONSE DE LAMARTINE, Correspondance. Lettres d'Alix de Lamartine. Lettres de Louis de Vignet, textes réunis, classés et annotés par Christian CROISILLE, avec la collaboration de Valérie CROISILLE, Paris, Honoré Champion, «Textes de littérature moderne et contemporaine», 2008 , pp. 669.

1 Après le dernier tome de la deuxième série de la Correspondance de Lamartine, ce volume nous offre, avec index des œuvres et des noms propres, les 167 lettres adressées par sa mère Alix au poète de 1814 à 1829 et 80 lettres de l'autre ami de sa jeunesse (à côté d'Aymon de Virieu), Louis de Vignet, de 1811 à 1836. L'une est comblée, après bien des soucis, par le mariage de son fils, les débuts de sa carrière diplomatique et son succès littéraire; l'autre croit voir un alter ego en cet ami qui pourtant ne partagera pas au fil des ans ses idées politiques et religieuses. C'est donc l'histoire juvénile de la formation de la personnalité lamartinienne que nous offre cette double publication de correspondants privilégiés par l'intimité.

Les lettres de cette mère que Lamartine qualifiera de «créature vraiment surhumaine», reconnaissant avoir été «la pensée de toute sa vie, le sentiment de toute son âme» (11 décembre 1829, Correspondance, 2, V, p. 499) témoignent en effet de l'amour attentif et dévoué qu'elle lui manifesta sans cesse. Cette femme pieuse sans être austère, qui avait épousé le frère de son amie de pension Suzanne, future Mme du Villard, était «une excellente maîtresse de maison et une exploitante de vignobles compétente et avisée» (introduction, p. 13) à laquelle son mari, plus amateur de chasses que de gestion de son domaine, s'en remettait largement. Les lettres ici réunies - pour leur majorité 
présentes dans la dation Lamartine à la Bibliothèque nationale de France en 2004, d'autres, également issues des archives de Saint-Point, mais passées en ventes publiques - confirment le portrait brossé par le Manuscrit de ma mère publié en 1871 avec maintes retouches du fils sur le journal réellement tenu par Alix. Leur publication séparée, que l'éditeur justifie par des retards techniques dus à des difficultés de datation et d'accessibilité des documents, s'explique aussi par le sens relativement unique de la correspondance conservée, du moins pour l'adolescence d'Alphonse qui a peut-être détruit ses propres missives. Le journal repris en juin 1801, alors que son fils vient d'être placé en pension à Lyon, plus tard à Belley, complète la connaissance de ces années tourmentées: les craintes maternelles sur le tempérament dépensier d'Alphonse, sa santé assez fragile, son indolence à entretenir des liens familiaux assez serrés à son goût avec oncles et tantes, les tentations auxquelles il risque de succomber par désœuvrement s'ébauchent dès lors et constituent les thèmes récurrents des lettres adressées de 1814 à 1829. Cette femme qui ne «se lasser[a] jamais de [s]on métier de mère» (23 avril 1816), qu'elle exerce avec autant d'attention au bénéfice de ses cinq filles, voit peu à peu cependant ses inquiétudes faire place à la joie. La poésie, d'abord perçue comme «joli talent de société» (en 1816), mais risquant d'exalter «le langage des passions» (23 février 1823) au lieu de chanter la religion, finit par s'avérer source de gloire par le succès des Méditations, reconnaissance des dons divins dans la nature des Harmonies et, finalement, juste avant la mort accidentelle de la mère, couronnement académique. Les déboires sur la vaine quête d'une place dans la haute administration puis la diplomatie du jeune garde du corps sous la Restauration sont enfin effacés par la nomination consulaire à Florence et le bonheur qui s'en suit pendant quatre ans. Les vaines démarches pour assurer un beau mariage, sur fond de liaisons devinées plus que confiées, s'effacent devant la confiance accordée à la douce Marianne, compagne des belles heures italiennes comme du retour à Saint-Point. Seule la question d'argent continue à tarauder, à fort juste titre, malgré les héritages successifs vite compromis par des dépenses excessives.

En revanche, la générosité est aussi la cause de cette inconscience budgétaire: si Lamartine doit emprunter à son ami, Louis de Vignet, l'autre épistolier de cette édition, il sait aussi prêter dans ses moments difficiles à celui qui va devenir son beau-frère par le mariage de Césarine. Cet autre ami de Belley, qui correspond aussi avec Aymon de Virieu, a laissé 78 lettres conservées, elles aussi à Saint-Point, et désormais à la BnF, écrites de 1811 à 1836, date de son décès. Ce Savoyard violemment pris du mal-être romantique durant sa jeunesse finit par accomplir une carrière diplomatique secrétaire d'ambassade à Londres, chargé d'affaires à Bruxelles, ministreplénipotentiaire à Berne, puis à Naples - plus durable que celle de son célèbre ami, dont les opinions religieuses et politiques s'écartent progressivement, au point de susciter une quasi-rupture courtoise après 1830. En effet ce libre-penseur originel devient un dévot convaincu qui tolère mal Jocelyn après avoir apprécié Les Harmonies; son conservatisme, de plus en plus accentué sous l'influence de Bonald et de son oncle Joseph de Maistre, lui fait mal supporter le libéralisme du futur député. Les rares lettres de Lamartine à Vignet (sans doute par destruction de ses héritiers) justifient mieux l'édition séparée de cette correspondance qui brosse en creux le portrait du poète par le contraste même de leur évolution, offrant un autre point de vue que celui vécu dans l'harmonie avec Virieu qu'a édité Marie-Renée Morin (Correspondance Lamartine-Virieu, P.U.F., 1987-1998, 4 tomes). 